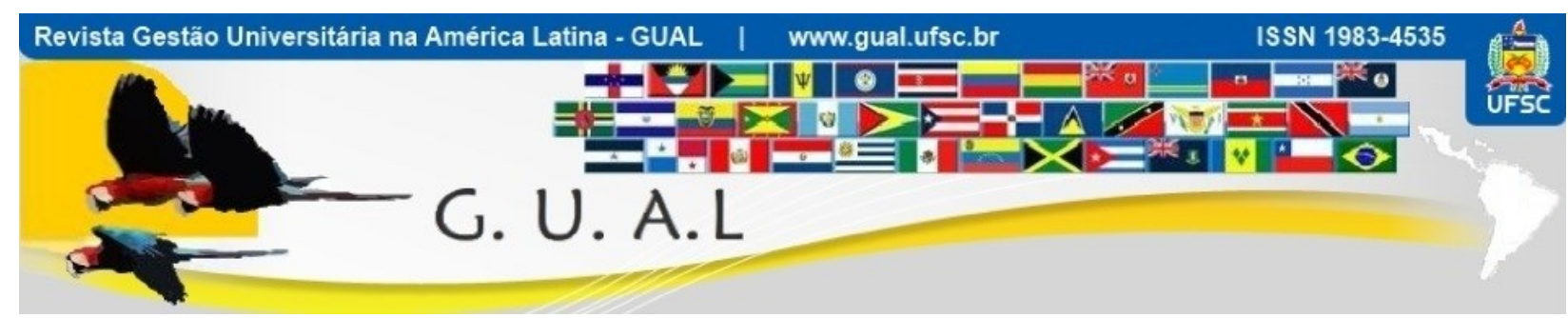

DOI: http://dx.doi.org/10.5007/1983-4535.2019v12n1p25

\title{
OS FATORES QUE INFLUENCIAM NO CLIMA ORGANIZACIONAL EM INSTITUIÇÕES FEDERAIS DE ENSINO SUPERIOR: UMA INVESTIGAÇÃO EM BELÉM DO PARÁ, BRASIL
}

\section{FACTORS INFLUENCING THE ORGANIZATIONAL CLIMATE IN FEDERAL INSTITUTIONS OF HIGHER EDUCATION: AN INVESTIGATION IN BELÉM, PARÁ, BRAZIL}

Carlos André Corrêa de Mattos, Doutor https://orcid.org/0000-0002-3027-7479 carlosacmattos@hotmail.com

Universidade Federal do Pará | Instituto de Ciências Sociais Aplicadas | Faculdade de Administração | Mestrado em Gestão Pública Belém do Pará | Pará | Brasil

Nilson Luiz Costa, Doutor http://orcid.org/0000-0003-2000-1521 nilson.costa@ufsm.br Universidade Federal de Santa Maria | Departamento de Ciências Econômica | Programa de Pós-Graduação em Agronegócios Palmeira das Missões | Rio Grande do Sul | Brasil

Ícaro Saraiva Laurinho, Bacharel https://orcid.org/0000-0003-1648-8752 icarolaurinho@gmail.com

Universidade Federal do Pará | Faculdade de Ciências Contábeis | Laboratório de Inovação e Controle no Setor Público Belém do Pará | Pará | Brasil

Lidiane Nazará da Silva Dias, Doutora https://orcid.org/0000-0003-0012-2510

lidianedias@ufpa.br Universidade Federal do Pará $\mid$ Faculdade de Ciências Contábeis Belém do Pará | Pará | Brasil

Recebido em 25/setembro/2017

Aprovado em 29/outubro/2018

Publicado em 02/janeiro/2019

Sistema de Avaliação: Double Blind Review

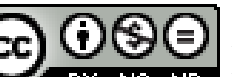

Esta obra está sob uma Licença Creative Commons Atribuição-Uso. 


\title{
OS FATORES QUE INFLUENCIAM NO CLIMA ORGANIZACIONAL EM INSTITUIÇÕES FEDERAIS DE \\ ENSINO SUPERIOR: UMA INVESTIGAÇÃO BELÉM DO PARÁ, BRASIL \\ DOI: http://dx.doi.org/10.5007/1983-4535.2019v12n1p25
}

\section{RESUMO}

O clima organizacional pode ser conceituado como o produto da percepção compartilhada pelos trabalhadores da qualidade do ambiente de trabalho em um dado momento. Ao longo do tempo, os estudos de clima organizacional mostraram relações com diversos aspectos do comportamento humano, com motivação, produtividade, comprometimento, entre outros. Desta forma, compreender o clima organizacional se tornou uma forma privilegiada de investigar o ambiente de trabalho. Nesse contexto, o objetivo deste estudo foi analisar os aspectos do ambiente de trabalho que exercem influência na formação do clima organizacional em instituições federais de ensino. A investigação utilizou método exploratório e descritivo na forma de pesquisa de campo em duas instituições na cidade de Belém do Pará, Brasil. A amostragem foi não probabilística por acessibilidade e obteve 236 entrevistas válidas. O tratamento de dados foi quantitativo com análise fatorial exploratória (AFE) e regressão linear múltipla (RLM). A análise fatorial captou quatro fatores que explicaram $65,25 \%$ da variância dos dados e foram denominados como Chefia $(18,97 \%)$, Imagem organizacional (17,57\%), Treinamento $(17,41 \%)$ e Remuneração $(11,30 \%)$. A regressão linear múltipla, com r-quadrado de 70,81\%, mostrou que o modelo era capaz de influenciar fortemente no clima organizacional. Conclui-se que os gestores podem utilizar os fatores identificados neste estudo para fundamentar estratégias que contribuam para melhoria do clima organizacional nas instituições pesquisadas.

Palavras-chave: Gestão de Pessoas. Organizações Públicas. Análise Fatorial Exploratória. Escores Fatoriais. Regressão Linear Múltipla.

\begin{abstract}
The organizational environment can be conceptualized as the product of perception shared by workers about the work environment quality at one point. Over time, organizational climate studies show human behavior relationships under many aspects as motivation, productivity, commitment, among others. In this way, understanding the organizational climate has become a privileged way to investigate the work environment. In this context, the objective of this study was to analyze some work environment aspects that affect the formation of the organizational climate in federal educational institutions. The research used an exploratory and descriptive method under form of field research in two institutions of Belém City, Pará State, Brazil. Sampling was non-probabilistic by accessibility, performing 236 valid interviews. Data treatment was quantitative with exploratory factorial analysis (EFA) and multiple linear regression (MLR). The factor analysis caught four factors that explained $65.25 \%$ of the data variance and were denominated as Management (18.97\%), Organizational Image (17.57\%), Training (17.41\%), and Compensation (11.30\%). With r-squared of $70.81 \%$, the multiple linear regression showed that the model was capable to strongly influencing the organizational climate. It is concluded that managers can use the factors identified by this study to support strategies that contribute to improvement of the organizational climate in the researched institutions.
\end{abstract}

Keywords: People Management. Public Organizations. Exploratory Factorial Analysis. Factor scores. Multiple linear Regression. 


\section{OS FATORES QUE INFLUENCIAM NO CLIMA ORGANIZACIONAL EM INSTITUIÇÕES FEDERAIS DE \\ ENSINO SUPERIOR: UMA INVESTIGAÇÃO BELÉM DO PARÁ, BRASIL \\ DOI: http://dx.doi.org/10.5007/1983-4535.2019v12n1p25}

\section{INTRODUÇÃO}

O clima organizacional e suas relações com outros aspectos do comportamento humano nas organizações têm despertado o interesse de pesquisadores e gestores nos mais diversos setores da economia e na maioria dos países do mundo há mais de 50 anos, desde que Forehand e Gilmer (1964), Pelz e Andrews (1966) e Litwin e Stringer (1968) iniciaram as pesquisas nos Estados Unidos da América do Norte, instigados pelos estudos de McClelland (1961). Esse startup ensejou um amplo conjunto de modelos de avaliação com as mais diferentes dimensões e variáveis. Essa amplitude possibilitou que as pesquisas de clima assumissem a fronteira das investigações quando se tratasse de gestão de pessoas (KUBO et al., 2015)

Na perspectiva de Luz (2012, p.13), o "clima organizacional é a atmosfera psicológica que envolve, num dado momento, a relação entre a empresa e seus funcionários". Conforme o autor, a conceituação de clima reúne elementos fundamentais para a compreensão do ambiente organizacional como sua característica circundante e seu caráter interpretativo. Assim, o clima organizacional estende-se além dos aspectos materiais e tangíveis, uma vez que se refere àquilo que é percebido no entorno, e mais que isso, passa a ser compartilhado entre os trabalhadores. Essa perspectiva confere ao clima organizacional um caráter mutável e relativamente instável, o que justifica sua analogia com as condições atmosféricas na climatologia. Essa característica evidencia a necessidade de acompanhá-lo constantemente.

$\mathrm{Na}$ administração pública, a preocupação com o clima organizacional surgiu com a modernização da área de gestão de pessoas e como consequência de dois aspectos principais, o primeiro foi a necessidade de pessoal motivado e qualificado para implementar as políticas públicas (GEMELLI; FILIPPIM, 2010) e o segundo resultou das demandas sociais que emergiram pela globalização e desencadearam mudanças nos modelos de gestão da administração pública, inicialmente nos países anglo-saxões (SILVESTRE, 2010) e, posteriormente, em diversos países do mundo, chegando ao Brasil em meados da década de 1990 (DUTRA, 2013), período em que os cidadãos deixaram de ser considerados beneficiários e passaram a ser vistos como clientes dos serviços públicos, exigindo, com isso, uma nova forma de atuação dos servidores públicos.

Kjeldsen e Hansen (2016) destacam que, apesar de a administração púbica ter avançado em matéria de gestão de pessoas, ainda persistem focos de insatisfação entre os servidores, como presença de processos muito burocráticos, hierarquia rígida e objetivos 


\section{OS FATORES QUE INFLUENCIAM NO CLIMA ORGANIZACIONAL EM INSTITUIÇÕES FEDERAIS DE \\ ENSINO SUPERIOR: UMA INVESTIGAÇÃO BELÉM DO PARÁ, BRASIL \\ DOI: http://dx.doi.org/10.5007/1983-4535.2019v12n1p25}

pouco definidos. Assim, apesar dos avanços, ainda há um longo caminho a ser percorrido para que as políticas de pessoal na administração pública possibilitem efetivamente ganhos à sociedade em geral. Teixeira e Salomão (2013), ao se referirem à gestão de pessoas na administração pública nacional, criticam e advertem que as políticas destinadas aos servidores púbicos carecem de racionalidade sistêmica, principalmente quanto à gestão de cargos, salários e carreiras, além de aspectos de ordem legal, que, sucessivamente, criaram um emaranhado de acordos, agravados por negociações isoladas com categorias específicas de servidores, que tornaram a gestão de pessoas uma "espécie de colcha de retalhos desarmônica e amarrada" (p.35).

Muitos aspectos do cotidiano da administração pública são focos permanentes de conflitos entre os servidores e a própria administração. Dutra (2013) identifica, entre os principais, a diversidade de formas de contratação (estatutários, celetistas e comissionados), as condições de trabalho e as políticas salariais. O autor destaca ainda a necessidade de fortalecer a atuação mais participativa dos servidores como uma estratégia para modernizar a gestão de pessoas e adaptá-las, mais efetivamente, às propostas do modelo gerencial, que mesmo considerando o tempo de sua implantação, ainda desafia o Estado a repensar suas políticas, funções e, principalmente, seus mecanismos de gestão (COSTA, 2012).

Nesse contexto, as pesquisas de clima organizacional progressivamente se mostraram uma estratégia ampla e privilegiada para a investigação do ambiente de trabalho, capaz de possibilitar diagnósticos acurados, desenvolvidos sob medida para a organização, capazes de fundamentar ações que promovam um ambiente de trabalho motivador e produtivo. No âmbito das instituições de ensino, a valorização da educação intensificada na sociedade moderna pôs em foco a necessidade de maior eficiência e satisfação no trabalho nessas instituições (ARABACI, 2010), o que, em certa medida, justificou a atenção com o clima organizacional.

Desta forma, o presente estudo concentrou-se nessas instituições e buscou responder ao questionamento: quais fatores influenciam o clima organizacional de instituições federais de ensino superior? E quais desses fatores exercem maior influência na formação do clima organizacional? Para tanto, a investigação pesquisou duas instituições na região metropolitana da cidade de Belém do Pará e adotou como objetivo analisar os aspectos do ambiente de trabalho que influenciam na formação do clima organizacional em instituições federais de ensino. 


\section{OS FATORES QUE INFLUENCIAM NO CLIMA ORGANIZACIONAL EM INSTITUIÇÕES FEDERAIS DE \\ ENSINO SUPERIOR: UMA INVESTIGAÇÃO BELÉM DO PARÁ, BRASIL \\ DOI: http://dx.doi.org/10.5007/1983-4535.2019v12n1p25}

\section{REVISÃO DA LITERATURA}

\subsection{A GESTÃO DE PESSOAS NA ADMINISTRAÇÃO PÚBLICA BRASILEIRA}

Na administração pública brasileira, a preocupação com a gestão de pessoas assumiu destaque de forma progressiva, e isso pode ser percebido, tanto nas pesquisas científicas (MELLO; AMANCIO FILHO, 2010; SILVA; MELLO, 2013), quanto nas políticas de recursos humanos, cujo exemplo é o Plano Nacional de Desenvolvimento Pessoal (PNDP), instituído pelo Decreto Lei ${ }^{0}$ 5707, de 23 de fevereiro de 2006, que trouxe para o centro das discussões o desenvolvimento dos servidores públicos federais e reforçou o emprego de técnicas de gestão para fins de aperfeiçoamento de pessoal (BRASIL, 2006).

Assim, o advento do modelo gerencial ou da Nova Gestão Pública (NGP) alterou o paradigma da administração, ao deslocar as preocupações do Estado dos processos administrativos, típicos do modelo burocrático, para uma compreensão ampliada da atuação estatal, cada vez mais fundamentada na eficiência administrativa e na busca da satisfação dos cidadãos com os serviços públicos, reformulando, assim, a compreensão organizacional de uma perspectiva voltada eminentemente para o ambiente interno, para uma visão abrangente das responsabilidades da administração pública na promoção do desenvolvimento e na sua inserção na sociedade (SILVESTRE, 2010; MATIAS-PEREIRA, 2013).

Desta forma, no contexto do modelo gerencial, o desempenho do servidor público naturalmente ganhou destaque e, como reforça Dutra (2013), para melhorar a performance organizacional, há necessidade de fortalecer as relações humanas, uma vez que a atividade laboral é um aspecto essencial da vida humana, que, ao ser equilibrado, retorna com resultados positivos para a organização ao promover melhorias na execução das tarefas, aspecto que pode ser percebido pelos clientes externos. Luz (2012), por sua vez, adverte que a insatisfação no ambiente de trabalho favorece a indiferença e a desmotivação, que resultam em baixa qualidade dos produtos e serviços, aspectos incompatíveis com as necessidades das organizações públicas contemporâneas.

No processo de valorização do pessoal, as pesquisas de clima organizacional começaram a ser utilizadas como uma ferramenta para diagnosticar a qualidade do ambiente de trabalho na administração pública (MÓL et al., 2010). O clima tem sido considerado um constructo importante para as pesquisas organizacionais nos últimos anos (NOORDIN et al., 2013) e, apesar de a literatura proliferar, não existe uma única conceituação de clima que seja aceita pacificamente entre os pesquisadores (PUROHIT; WADHWA, 2012). Assim, a 


\section{OS FATORES QUE INFLUENCIAM NO CLIMA ORGANIZACIONAL EM INSTITUIÇÕES FEDERAIS DE \\ ENSINO SUPERIOR: UMA INVESTIGAÇÃO BELÉM DO PARÁ, BRASIL \\ DOI: http://dx.doi.org/10.5007/1983-4535.2019v12n1p25}

diversidade de concepções teóricas, aliada às diversas perspectivas de análise do clima e à necessidade de adequar as pesquisas às peculiaridades de cada organização, originaram diversos modelos para avaliar o clima organizacional, muitos deles desenvolvidos sob a perspectiva de setores específicos da economia (KUBO et al., 2015).

\subsection{CLIMA ORGANIZACIONAL: CARACTERÍSTICAS E PESQUISAS}

Boog e Boog (2012) conceituam clima organizacional como "a satisfação dos colaboradores com diversos aspectos de suas relações e seus trabalhos" (p.26). Contudo, Martins (2008) adverte para os cuidados que devem ser tomados ao conceituar o clima organizacional e assim evitar a sobreposição de conceitos diferentes. A autora exemplifica sua recomendação ao discorrer sobre a conceituação de clima psicológico, satisfação com o trabalho e cultura organizacional, reforçando que cada um deles apresenta peculiaridades específicas que os diferenciam dos demais, inclusive de clima organizacional

A compreensão do clima organizacional, conforme Luz (2012), é constituída por três aspectos inter-relacionados: o primeiro é a cultura organizacional; o segundo é a percepção dos trabalhadores; e o terceiro é a satisfação obtida por trabalhar na organização. Diversos estudos (SANTOS, 1999; MÓL et al., 2010; GONÇALVES, 2012; HOLLOWAY, 2012), resgatam a conceituação de clima organizacional proposta por Litwin e Stinger (1968), que compreende o clima como um conjunto de características presentes e mensuráveis do ambiente de trabalho, que podem ser percebidas pelos trabalhadores como boas ou más e que exercem influência na motivação e no comportamento. Na obra, Litwin e Stinger (1968) definiram o clima de forma subjetiva como uma qualidade do ambiente organizacional experimentada pelos integrantes da organização, mensurável desde que utilizado o instrumento correto.

Ao considerar as características do clima organizacional em diversos estudos (GHANBARI; ESKANDARI, 2009; MÓL et al. 2010; NOODIN et al., 2013), emergem dois aspectos que merecem destaque. O primeiro é que não há uniformidade nas dimensões utilizadas nas pesquisas de clima, assim os estudos apresentam um amplo e variado conjunto de dimensões e indicadores de mensuração. Essa peculiaridade faz com que os modelos sejam fundamentados em diferentes perspectivas organizacionais sob medida, como forma de (1) adequar os instrumentos de coleta de dados às peculiaridades da organização, (2) aos objetivos das pesquisas, ou ainda (3) das diferentes perspectivas teóricas dos pesquisadores. 


\section{OS FATORES QUE INFLUENCIAM NO CLIMA ORGANIZACIONAL EM INSTITUIÇÕES FEDERAIS DE \\ ENSINO SUPERIOR: UMA INVESTIGAÇÃO BELÉM DO PARÁ, BRASIL \\ DOI: http://dx.doi.org/10.5007/1983-4535.2019v12n1p25}

Outro aspecto é detalhado em Martins (2008) ao diferenciar clima de cultura organizacional. Assim, o clima tem por essência ser superficial e mutável, assumindo a cultura uma dimensão mais profunda e estável. Desta forma, uma organização pode ter uma cultura e diversos climas, dependendo do momento e da unidade administrativa em estudo. Essa característica assume destaque para a gestão, pois como a cultura é mais difícil de ser mudada, os esforços se voltam para o clima como estratégia mais imediata de intervenção e como forma de mudar a cultura em dimensão temporal mais longa (STRINGER, 2002; HONG; KAUR, 2008).

Essencialmente, o clima e a cultura organizacional mantêm uma relação próxima ao considerar que o clima é influenciado fortemente pela cultura e a cultura, por sua vez, manifesta-se diariamente na organização pelo seu conjunto de regras, normas, costumes, histórias, rituais e outros. Portanto, o clima revela, em grande parte, como os trabalhadores percebem a cultura organizacional e reagem a ela (MARTINS, 2008; LÜCK, 2011; LUZ, 2012; GONÇALVES, 2012). Bergue (2011, p.534) reforça que a cultura da organização reúne um "conjunto de hábitos, crenças, valores e símbolos que a particularizam frente às demais. Pode-se, então, sem demasiado esforço, elencar traços da cultura tendo em vista o convívio e a interação com a estrutura, os processos e, sobretudo, com as pessoas".

No serviço público, aspectos específicos da cultura organizacional se manifestam com diferentes intensidades, dependendo da organização, sendo que algumas questões peculiares diferenciam as organizações públicas das organizações privadas. Entre essas questões, destacam-se as condecorações, as honrarias, os ritos e as solenidades e, de forma mais específica na gestão de pessoas, o reduzido grau de insegurança, a constância no ritmo de trabalho, a estabilidade e a baixa sensibilidade a turbulências do ambiente externo, a ênfase nas relações pessoais e grupais, além de traços de paternalismo, materializados em licenças, vantagens e concessões especiais, benefícios inseridos na legislação (BERGUE, 2011).

Isso posto, percebe-se que as pesquisas de clima organizacional constituem um amplo campo de estudos organizacionais, que tem despertado o interesse de diversos pesquisadores (OLIVEIRA; 2008; CONTRERAS et al. 2009; MATIAS, 2010, NOORDIN et al. 2013; HOLLOWAY, 2012), além disso, seus achados têm contribuído expressivamente para melhorar a gestão organizacional ao identificar entre o conjunto de percepções compartilhadas pelos trabalhadores que elas que podem influenciar mais fortemente suas atitudes perante o trabalho (SANTOS, 1999). Com isso, é possível melhorar a compreensão de como os 


\section{OS FATORES QUE INFLUENCIAM NO CLIMA ORGANIZACIONAL EM INSTITUIÇÕES FEDERAIS DE ENSINO SUPERIOR: UMA INVESTIGAÇÃO BELÉM DO PARÁ, BRASIL DOI: http://dx.doi.org/10.5007/1983-4535.2019v12n1p25}

trabalhadores convivem entre si e exercem suas tarefas cotidianas. Concentrar-se nessas questões contribui para a escolha das estratégias mais adequadas para cada organização, que promovam a integração, de tal forma a favorecer ações conjuntas e possibilitar a obtenção dos objetivos organizacionais (MOTA; SILVA; PORTO, 2008; SANTOS, 1999).

A dimensão abrangente do clima organizacional tem possibilitado sua articulação conceitual com outros aspectos da gestão de pessoas e do comportamento organizacional, como a motivação e a satisfação com o trabalho (MÓL et al., 2010). Holloway (2012) destaca que as pesquisas de clima têm indicado que suas dimensões, como o estilo de liderança, recompensas e o sentimento de companheirismo, influenciam favoravelmente no desempenho das equipes, aumentando o comprometimento e reduzindo as ausências ao trabalho. Essas constatações confirmam os postulados de Litwin e Stringer (1968), que consideram que o clima organizacional recebe forte influência da liderança.

Martins (2008) afirma que, analisado sob a ótica dos trabalhadores, o clima organizacional pode influenciar em suas ações, reações e decisões, de forma a trazer impactos para a organização. Esses aspectos apresentam reflexos na satisfação com o trabalho, motivação, produtividade, da mesma forma como impactam na qualidade de vida e otimizam o desempenho da organização. Boog e Boog (2012), ao discorrem sobre os benefícios das pesquisas de clima afirmam que esses estudos contribuem para entender melhor a saúde organizacional e os comparam às pesquisas de clima como check ups que devem ser feitos periodicamente para antever possíveis problemas e corrigi-los antes que se agravem.

Stringer (2002), ao discorrer sobre o Modelo de Desempenho Organizacional, conforme a Figura 1, mostra as relações entre os elementos que influenciam no clima e na cultura organizacional. Conforme o modelo, a motivação e o desempenho individual e grupal são o resultado de um amplo conjunto de forças, que, atuando conjuntamente tanto no clima, quanto na cultura organizacional, juntas, são capazes de influenciar no desempenho da organização. Entre essas forças estão o ambiente externo, a estratégia organizacional, as práticas de liderança, os planos organizacionais e as forças históricas. $\mathrm{O}$ autor ratifica que a cultura organizacional, por ser mais profunda e estável, é mais difícil de ser gerenciada, assim, intervir no clima é uma alternativa para melhorar o desempenho organizacional de maneira mais imediata. 
Figura 1 Modelo de desempenho organizacional

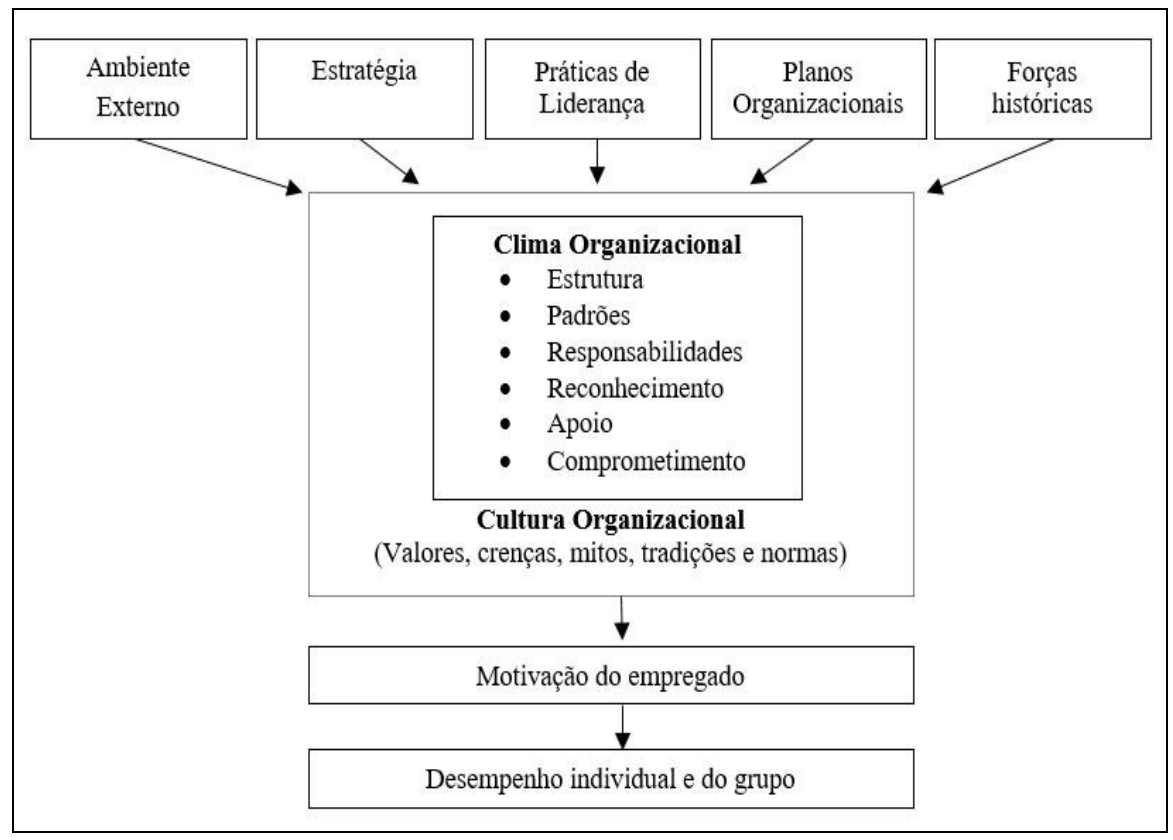

Fonte: Stringer (2002, p.18).

Luz (2012) reforça que acompanhar os indicadores do clima organizacional fornece elementos para descobrir as causas que influenciam negativamente o ambiente de trabalho. $\mathrm{O}$ autor destaca que alguns acontecimentos são indicativos da necessidade de realização de pesquisas de clima organizacional, entre eles estão a alta rotatividade de pessoal e os elevados índices absenteísmo, críticas e agressões anônimas aos gestores, pichações, programas de sugestões malsucedidos, baixa produtividade, entre outros. Nesse sentido, Luz (2012) considera que as pesquisas de clima podem antecipar problemas e fornecer insights sobre o ambiente de trabalho.

As contribuições das pesquisas de clima para o ambiente de trabalho se espalham pelo mundo. Alguns exemplos, são Noodin et al. (2013), que, ao investigarem as dimensões do clima organizacional em uma universidade pública na Malásia, constataram níveis intermediários de clima organizacional e assim propuseram estratégias para melhorar o ambiente de trabalho da instituição; Ghanbari e Eskandari (2009), que reforçam que as pesquisas de clima organizacional têm contribuído para aumentar o conhecimento do comportamento humano e, ao aplicarem um estudo empírico, constataram que havia correlação positiva e significativa entre o clima e a cidadania organizacional, tendo, no mesmo estudo, identificado que a satisfação com as recompensas e a clareza de objetivos contribuíam positivamente para a motivação. 


\section{OS FATORES QUE INFLUENCIAM NO CLIMA ORGANIZACIONAL EM INSTITUIÇÕES FEDERAIS DE \\ ENSINO SUPERIOR: UMA INVESTIGAÇÃO BELÉM DO PARÁ, BRASIL \\ DOI: http://dx.doi.org/10.5007/1983-4535.2019v12n1p25}

Nesse contexto, pesquisar o clima organizacional se mostra relevante sob diversas perspectivas, que compreendem desde aspectos científicos a questões gerenciais e de políticas de gestão de pessoas. Portanto, aprofundar os estudos de clima organizacional no serviço público, em especial, pode trazer benefícios, uma vez que essas investigações podem contribuir para a compreensão das dimensões específicas do clima organizacional, que se manifestem de forma diferente no serviço público, uma vez que, como destaca Bergue (2011), as organizações públicas apresentam peculiaridades que as diferenciam das organizações privadas e que têm sido objeto da maioria das investigações de clima organizacional (MÓL et al., 2010).

Em síntese, compreender o ambiente de trabalho das organizações públicas pode trazer subsídios que propiciem melhores condições de trabalho, nas quais a atividade laboral seja motivadora, participativa e rica em experiências construtivas, melhorando assim a realização profissional do servidor e a qualidade de vida no trabalho, com isso facilitando o processo de gestão pela utilização de estratégias mais bem direcionadas, que promovam um ambiente de trabalho moderno e com engajamento dos trabalhadores, que resulte em melhores patamares na prestação de serviços públicos.

\section{PROCEDIMENTOS METODOLOGICOS}

A pesquisa foi conduzida em duas instituições federais de ensino superior na região metropolitana de Belém do Pará, a Universidade Federal Rural da Amazônia (UFRA) e o Instituto Federal de Educação, Ciência e Tecnologia do Pará (IFPA). As técnicas utilizadas caracterizaram uma pesquisa aplicada, uma vez que se concentrou em problemas reais do cotidiano dessas organizações (SAMPIERI; COLLADO; LUCIO, 2013). Essa característica conferiu ao estudo um aspecto prático ao investigar as dimensões que exerciam maior influência na formação do clima organizacional. Quanto à natureza, o método caracterizou um estudo exploratório e descritivo, e quanto aos procedimentos, uma pesquisa de campo, pois a investigação ocorreu no mesmo local do fenômeno (MARCONI; LAKATOS, 2008; MATINS; THEÓPHILO, 2016).

O universo de pesquisa foi formado por servidores públicos federais de duas categorias profissionais, (1) professores e (2) técnicos administrativos, ambos lotados nas instituições pesquisadas. Quanto aos procedimentos, eles foram divididos em duas etapas: a primeira, de caráter exploratório, foi iniciada com uma consulta a dados secundários e 
entrevistas com gestores. Essa fase teve o propósito contribuir para a compreensão do ambiente de trabalho e identificar, entre as diversas dimensões utilizadas nas pesquisas de clima organizacional, quais eram as mais adequadas para a investigação. O produto da fase exploratória foi a elaboração do questionário. A segunda etapa foi descritiva, caracterizada pela aplicação dos questionários na forma de pesquisa de campo e posterior tratamento dos dados.

A etapa descritiva foi iniciada com o pré-teste do questionário, que não demandou alterações, pois foi rápida e facilmente entendido e respondido pelos entrevistados. O questionário foi autoaplicável e organizado em duas seções. A primeira seção reuniu 42 assertivas com respostas em escala intervalar de Likert, sendo 1 totalmente insatisfeito, 2 parcialmente insatisfeito, 3 nem insatisfeito, nem satisfeito, 4 parcialmente satisfeito e 5 totalmente satisfeito. Esse tipo de escala tem como vantagem possibilitar mensurar a intensidade de concordância (ou discordância) do entrevistado quanto à assertiva em investigação (COSTA, 2011).

As assertivas do questionário foram reunidas em nove dimensões que refletiam aspectos do clima organizacional. Essas foram: comunicação organizacional, imagem organizacional, cooperação, remuneração e recompensa, satisfação com o trabalho, equidade, participação nas decisões, valorização do servidor e modernidade organizacional. A segunda seção do questionário foi formada por questões de caracterização dos entrevistados, especialmente quanto a aspectos socioeconômicos. As questões dessa seção foram elaboradas com respostas dicotômicas e de múltipla escolha e investigaram características como escolaridade, gênero, tempo de experiência profissional, cargo, formação acadêmica, entre outras.

A amostragem utilizada na investigação foi não probabilística por acessibilidade. Essa técnica não permite o cálculo do erro amostral, limitando os resultados à amostra investigada (SAMPIERI; COLLADO; LUCIO, 2013). Ao final da pesquisa de campo, foram obtidos 236 questionários de pesquisas válidos. Os entrevistados foram informados dos riscos da pesquisa e assinaram o Termo de Consentimento Livre e Esclarecido (TCLE), conforme padrões éticos de pesquisas com seres humanos.

O tratamento dos dados foi quantitativo e utilizou técnicas multivariadas, especificamente a análise fatorial exploratória (AFE), selecionada por sua capacidade para sumarizar informações e identificar fatores latentes, e a regressão linear múltipla (RLM), 
escolhida para testar o modelo e identificar o quanto da avaliação geral do clima organizacional (variável dependente) poderia ser explicada pelos fatores expressos na forma de escores fatoriais (variáveis independentes). Essas técnicas foram empregadas como recomendam Cunha e Coelho (2009), Dillon e Goldstein (1984), Hair et al. (2009) e Fávero et al. (2009). O modelo de análise fatorial (1) pode ser representado, conforme Dillon e Goldstein (1984):

$$
\mathrm{X}=\alpha \mathrm{F}+\varepsilon,
$$

Em que: $X$ é o p-dimensional, vetor transposto das variáveis observáveis, denotado por $\mathrm{X}=\left(\mathrm{x}_{1}, \mathrm{x}_{2} \ldots, \mathrm{x}_{\mathrm{p}}\right)^{\mathrm{t}} ; F$ é o q-dimensional, vetor transposto das variáveis não observáveis ou variáveis latentes, denominadas de "fatores comuns", denotados por $F=\left(f_{1}, f_{2}, \ldots, f_{q}\right)^{t}$, sendo $q$ $<\mathrm{p}$; $\varepsilon$ é o p-dimensional, vetor transposto de variáveis aleatórias ou fatores únicos, $\varepsilon=\left(\mathrm{e}_{1}\right.$, $\left.\mathrm{e}_{2}, \ldots, \mathrm{e}_{\mathrm{p}}\right)^{\mathrm{t}}$; e $\alpha$ é a matriz (p, q) de constantes desconhecidas, identificadas como "cargas fatoriais".

Quanto aos escores fatoriais (2) eles têm como principais características (1) serem padronizados (Z-score) e (2) poderem substituir as variáveis originais (HAIR et al., 2009 e FÁVERO et al., 2009). Os escores são expressos conforme Mingoti (2007):

$$
\hat{F}_{i j}=w_{j 1} Z_{1 k}+w_{j 2} Z_{2 k}+\cdots+w_{j p} Z_{p k}
$$

Em que $\left(Z_{1 k} Z_{2 k} \ldots Z_{p k}\right)$, são os valores observados das variáveis padronizadas $Z_{\mathrm{i}}$ para o k-ésimo elemento amostral e os coeficientes $\mathrm{w}_{\mathrm{ip}} \mathrm{i}=1,2, \ldots$ p são os pesos de ponderação de cada variável $Z_{i}$ no fator $F_{j}$.

Quanto à regressão linear múltipla (3), trata-se de uma técnica que tem por finalidade “estimar uma função matemática que busca descrever o comportamento de determinada variável, denominada dependente, com base nos valores de uma ou mais vaiáveis, denominadas independentes" (CUNHA; COELHO, 2009, p. 132). No contexto deste estudo, a variável dependente foi a avaliação geral do clima organizacional, expressa pelas respostas dos entrevistados para a assertiva "No geral, estou satisfeito com o clima organizacional no meu local de trabalho", e as variáveis independentes, expressas pelos valores do escores fatoriais.

$$
Y=\beta_{0}+\beta_{1} x_{1}+\beta_{2} x_{2}+\cdots+\beta_{n} x_{n}+\varepsilon
$$

Em que: Y é a variável dependente; $x_{1}, x_{2}, \ldots x_{\mathrm{n}}$ são variáveis independentes; $\beta_{0}, \beta_{1}, \beta_{2}$, ..., $\beta_{\mathrm{n}}$ são os parâmetros da regressão; e $\varepsilon$ é o termo de erro ou o resíduo da regressão. 
O questionário assim como os fatores foram avaliados quanto a fidedignidade pela utilização do coeficiente Alpha de Cronbach (4), que é a técnica mais utilizada nas pesquisas para avaliação da consistência interna, uma vez que permite avaliar se respostas obtidas pela pesquisa de campo se repetiriam se o mesmo instrumento fosse aplicado à mesma amostra (COSTA, 2011).

$$
\alpha=\frac{\mathrm{k}}{\mathrm{k}-1}\left(1-\frac{\sum_{i=1}^{\mathrm{k}} \sigma_{i}^{2}}{\sigma_{\mathrm{Y}}^{2}}\right)
$$

Em que: $\mathrm{k}$ é o número de itens do questionário; $\sigma_{\mathrm{i}}{ }^{2}$ é a variância do item $\mathrm{i}$; e $\sigma_{\mathrm{y}}{ }^{2}$ é a variância da escala total somada.

\section{APRESENTAÇÃO DE RESULTADOS}

A amostra foi formada por 236 (100\%) servidores públicos de suas instituições federais de ensino, ambas localizadas na cidade de Belém do Pará, sendo 48,3\% (114) da Universidade Federal Rural da Amazônia (UFRA) e 51,7\% (122), do Instituto Federal de Educação, Ciência e Tecnologia do Pará (IFPA). Quanto aos cargos, a composição da amostra foi formada por 54,2\% (128) de técnicos administrativos e 45,8\% (108) de professores, ambos ocupantes de cargos efetivos em 92,8\% (219) das observações. Os entrevistados revelaram escolaridade elevada, uma vez que 90,2\% (213) declararam ter curso superior e 48,7\% (115), mestrado ou doutorado.

Quanto ao gênero, ocorreu leve predominância do sexo masculino, com 50,4\% (119) das observações, 51,3\% (121) eram casados, e a idade média foi de 40 anos ( \pm 10 anos). Quanto ao tempo de atuação na instituição, na ocasião da entrevista os participantes tinham em média 10 anos ( \pm 9 anos) de experiência, sendo que 31,35\% (74) exerciam cargo de chefia. A remuneração média posicionou-se no intervalo entre $\mathrm{R} \$ 4.862,00$ e $\mathrm{R} \$ 9.897,00$, sendo essa a alternativa escolhida por 40,2\% (95) dos entrevistados. Foi observado que $75 \%$ (177) dos entrevistados recomendariam a organização para outros profissionais trabalharem.

\subsection{ANÁLISE FATORIAL EXPLORATÓRIA}

A análise fatorial, Tabela 1, foi iniciada pela verificação da adequação da amostra à técnica, tendo esse procedimento revelado ótimo ajustamento. A determinante da matriz foi positiva $(8,44 \mathrm{E}-007)$, o número de observações por variável foi adequado $(10,72)$ e as correlações foram superiores a 0,30 alcançaram $80,31 \%$ da matriz, sendo 99,35\% significativas a $1 \%$. Nessas condições, o teste Kayser-Meyer-Oklim $(\mathrm{KMO}=0,924)$ e o de 


\section{OS FATORES QUE INFLUENCIAM NO CLIMA ORGANIZACIONAL EM INSTITUIÇÕES FEDERAIS DE ENSINO SUPERIOR: UMA INVESTIGAÇÃO BELÉM DO PARÁ, BRASIL DOI: http://dx.doi.org/10.5007/1983-4535.2019v12n1p25}

esfericidade de Bartlett $\left(\chi^{2}=3.172,24\right.$, significativo a $\left.1 \%\right)$ confirmaram a adequação dos dados à técnica.

Atendidos os pressupostos iniciais, os fatores foram extraídos pela análise de componentes principais (ACP), com rotação ortogonal Varimax, e com a utilização do critério do autovalor, segundo o qual, cada fator deve ser capaz de explicar minimamente a própria variância (FÁVERO et al., 2009; HAIR et al., 2009). A análise fatorial possibilitou reduzir a matriz das 46 assertivas originais para 22, reunidas em quatro fatores, que explicaram, em conjunto, $65,25 \%$ da variância total dos dados e mostraram elevada consistência interna, tanto para os fatores em conjunto $(\alpha=0940)$, quanto isoladamente, uma vez que todos os coeficientes alpha de Cronbach foram superiores a $\alpha=0,815$.

As comunalidades $\left(\mathrm{h}^{2}\right)$ foram adequadas, tendo sido todas elas superiores a 0,522. Esse aspecto mostra que os fatores puderam explicar parcelas substanciais da variância das variáveis em estudo. A denominação dos fatores foi semântica e privilegiou a variável com maior carga fatorial, sendo o primeiro fator formado por sete variáveis, identificado como Chefia, o segundo com seis variáveis, denominado de Imagem Organizacional, o terceiro também com seis variáveis, identificado de Treinamento e o quarto fator, com três variáveis, foi identificado como Remuneração.

Tabela 1 Fatores, autovalores, variância explicada e Alpha de Cronbach

\begin{tabular}{clcccc}
\hline Fator & Denominação do fator & $\begin{array}{c}\text { Qtd. de } \\
\text { variáveis }\end{array}$ & Autovalor & $\begin{array}{c}\text { Variância } \\
\text { Explicada }\end{array}$ & $\begin{array}{c}\text { Alpha de } \\
\text { Cronbach }\end{array}$ \\
\hline F1 & Chefia & 7 & 4,17 & $18,97 \%$ & 0,877 \\
F2 & Imagem organizacional & 6 & 3,86 & $17,57 \%$ & 0,896 \\
F3 & Treinamento & 6 & 3,80 & $17,41 \%$ & 0,874 \\
F4 & Remuneração & 3 & 2,49 & $11,30 \%$ & 0,815 \\
\hline Total & & 22 & 14,32 & $65,25 \%$ & 0,940 \\
\hline
\end{tabular}

$\mathrm{KMO}=0,924$, Teste de esfericidade de Bartllet $\left(\chi^{2}\right)=3.172,24$, significante a $1 \%$.

Determinação do número de fatores pelo critério dos autovalores.

Extração dos fatores por ACP com rotação ortogonal pelo método Varimax.

Fonte: Pesquisa de campo.

O fator Chefia, fator principal, explicou $18,97 \%$ da variância e teve por base, essencialmente, a valorização das relações com os superiores hierárquicos (Tabela 2). Este fator captou a necessidade da livre expressão, da confiança nas informações, além do apoio dos chefes no desenvolvimento das tarefas. Assim, são valorizados os superiores hierárquicos que aceitam as sugestões de seus subordinados, que incentivam o trabalho em equipe e que 
avaliam os resultados do trabalho com imparcialidade. Outro aspecto captado pelo fator foi a integração dos novatos pelo acolhimento e auxílio dos servidores mais experientes, tarefa na qual as chefias podem contribuir fortemente. Holoway (2012) destaca que os trabalhadores representam um dos principais ativos organizacionais, pois são os mais capacitados para potencializar a criação de valor. O autor reforça que o clima organizacional e as lideranças são construtos entrelaçados sob diversas perspectivas e que a atuação das chefias é um dos principais precursores na formação do clima organizacional. Nesse sentido, observa-se convergência do entendimento do autor com outros estudos como os de Griffity (2006), Koene, Vogelaar e Soeters (2002) e Litwin e Stinger (1968).

Em complemento, Momeni (2009), ao discorrer sobre aspectos da liderança no clima organizacional, afirma que $70 \%$ da percepção geral do clima advém de como o trabalhador avalia o estilo do seu líder, sendo a liderança um forte influenciador de atitudes, comportamentos, moral, emoções e percepções dos trabalhadores. Griffity (2006) destaca que líderes apoiadores são mais capazes de promover um funcionamento eficaz da organização. Esses aspectos reforçam a necessidade de as organizações promoverem competências gerenciais entre suas chefias e dirigentes.

Tabela 2 Fator Chefia

\begin{tabular}{|c|c|c|}
\hline Variáveis & $\begin{array}{l}\text { Carga } \\
\text { Fatorial }\end{array}$ & $h^{2}$ \\
\hline $\begin{array}{l}\text { Meus superiores dão liberdade para os servidores expressarem livremente suas } \\
\text { opiniões quanto à organização e ao trabalho realizado }\end{array}$ & 0,769 & 0,675 \\
\hline Confio nas informações transmitidas pelos meus superiores hierárquicos. & 0,764 & 0,641 \\
\hline As chefias ajudam os servidores na execução das tarefas. & 0,733 & 0,619 \\
\hline $\begin{array}{l}\text { Percebo que há aceitação, por parte das chefias da organização, quanto às } \\
\text { contribuições sugeridas pelos servidores }\end{array}$ & 0,703 & 0,645 \\
\hline $\begin{array}{l}\text { Os servidores novatos são ajudados pelos colegas mais antigos no aprendizado das } \\
\text { tarefas }\end{array}$ & 0,668 & 0,522 \\
\hline Existe incentivo ao trabalho em equipe por parte de meus superiores hierárquicos. & 0,587 & 0,587 \\
\hline $\begin{array}{l}\text { O trabalho que desenvolvo é avaliado de maneira imparcial por meus superiores } \\
\text { hierárquicos. }\end{array}$ & 0,545 & 0,530 \\
\hline
\end{tabular}

Fonte: Pesquisa de campo.

O segundo fator, Imagem Organizacional, Tabela 3, explicou 17,57\% da variância dos dados e captou o prestígio de pertencer a uma organização orientada por valores éticos e reconhecida socialmente. Esse fator, com elevado componente social, é constituído por uma conduta ética e de respeito conquistado junto a outras organizações do serviço público. $\mathrm{O}$ fator exprime a valorização da justiça organizacional na distribuição das tarefas, a importância 


\section{OS FATORES QUE INFLUENCIAM NO CLIMA ORGANIZACIONAL EM INSTITUIÇÕES FEDERAIS DE ENSINO SUPERIOR: UMA INVESTIGAÇÃO BELÉM DO PARÁ, BRASIL DOI: http://dx.doi.org/10.5007/1983-4535.2019v12n1p25}

atribuída à satisfação dos usuários e as oportunidades de promoções com base no merecimento e profissionalismo. Esse conjunto de aspectos se relaciona diretamente com a forma como a organização compreende sua atuação e inserção na sociedade, que, por sua vez, é materializada no profissionalismo com o qual guia suas ações.

Nesse contexto, os efeitos da Imagem Organizacional junto à sociedade e sua conduta quanto a valores éticos não são uma inovação nas pesquisas de clima, uma vez que Sbragia (1983) já destacava, no modelo de sua autoria, que a sensação de pertencimento, quando associada a uma organização de elevado prestigio social, contribui para o estabelecimento de um melhor clima organizacional.

Tabela 3 Fator Imagem Organizacional

\begin{tabular}{lccc}
\hline Variáveis & $\begin{array}{c}\text { Carga } \\
\text { Fatorial }\end{array}$ & $\mathrm{h}^{2}$ \\
\hline Percebo que a organização em que trabalho tem boa imagem perante a sociedade. & 0,805 & 0,778 \\
Noto que a atuação da organização em que trabalho é guiada por valores éticos. & 0,783 & 0,761 \\
A organização que trabalho é respeitada pelas outras organizações federais. & 0,742 & 0,704 \\
Na organização em que trabalho há justiça na distribuição das tarefas entre os & 0,678 & 0,670 \\
servidores. & 0,605 & 0,643 \\
Noto que os usuários estão satisfeitos com os serviços oferecidos pela organização. & 0,599 & 0,611 \\
\hline Percebo que tenho oportunidades de ser promovido e ascender profissionalmente. & 0,5 &
\end{tabular}

Fonte: Pesquisa de campo

O terceiro fator Treinamento, Tabela 4, explicou 17,41\% da variância dos dados e captou a possibilidade de aprimoramento e qualificação profissional. Assim, as oportunidades de capacitação oferecidas aos servidores, o aproveitamento dos novos conhecimentos e habilidades na realização das tarefas, além da satisfação e motivação com o qual o trabalho realizado, materializados nas possibilidades de construção de uma carreira proporcionada pelas oportunidades de promoções e pelo acesso aos cargos de maior prestígio profissional, foram elementos captados pelo fator.

Rueda, Santos e Lima (2012, p. 134) em complemento, destacam que existe organizacionalmente uma correlação forte e significativa $(0,73 ;$ sig. $=0,01 \%)$ entre o desenvolvimento profissional, resultado de capacitações e treinamentos, e a satisfação com as promoções. Stringer (2002), por outro lado, reforça a proximidade entre o clima e o desempenho organizacional. Para o autor, quando mais o clima organizacional for favorável, maior será sua capacidade de influenciar positivamente no desempenho da organização 


\section{OS FATORES QUE INFLUENCIAM NO CLIMA ORGANIZACIONAL EM INSTITUIÇÕES FEDERAIS DE ENSINO SUPERIOR: UMA INVESTIGAÇÃO BELÉM DO PARÁ, BRASIL DOI: http://dx.doi.org/10.5007/1983-4535.2019v12n1p25}

Tabela 4 Fator Treinamento

\begin{tabular}{|c|c|c|}
\hline Variáveis & $\begin{array}{l}\text { Carga } \\
\text { Fatorial }\end{array}$ & $h^{2}$ \\
\hline $\begin{array}{l}\text { Jo meu local de trabalho, há oportunidades de treinamento e desenvolvimento } \\
\text { rofissional. }\end{array}$ & 0,750 & 0,663 \\
\hline $\begin{array}{l}\text { Recebo treinamento para desenvolver as atividades que são de minha } \\
\text { responsabilidade. }\end{array}$ & 0,693 & 0,699 \\
\hline $\begin{array}{l}\text { leu aprendizado é aproveitado de forma adequada nas atividades que eu } \\
\text { esenvolvo na organização. }\end{array}$ & 0,662 & 0,67 \\
\hline feito com as tarefas aue decenvolve em meul traholhe diariamente & 0,650 & 0,530 \\
\hline $\begin{array}{l}\text { to-me motivado para desenvolver as tarefas que são da minha responsabilidade } \\
\text { organização. }\end{array}$ & 0,605 & 0,582 \\
\hline into realização profissional pelo trabalho que desenvolvo na organização. & 0,600 & 0,591 \\
\hline
\end{tabular}

Fonte: Pesquisa de campo.

Esses resultados, quando analisados à luz desse fator, indicam que existe a expectativa entre os servidores de que as ações de treinamento contribuam para oportunidades de ganhos salariais e promoções a cargos mais elevados na estrutura organizacional no futuro. Resultados semelhantes foram encontrados por Klein e Mascarenhas (2016), ao identificarem que a perspectiva de carreira se constituída pela expectativa de equidade na remuneração futura.

O fator Remuneração captou o reconhecimento ao trabalho expresso na forma de salários. Desta forma, a equidade dos rendimentos, tanto em comparação com outras instituições públicas, quanto com as organizações privadas, serve de parâmetro para a avaliação do salário recebido. As características desse fator são coerentes com as teorias motivacionais, especialmente a teoria da equidade, ao revelar que existe um processo comparativo da remuneração recebida com os valores pagos a trabalhadores que exercem tarefas semelhantes em outras organizações (KLEIN; MASCARENHAS, 2016). Nesse contexto, revela-se a necessidade que as organizações públicas têm em oferecer aos servidores um relativo equilíbrio de recompensas, tanto internamente entre suas organizações, quanto com o setor privado. A potencialidade da remuneração é reconhecida na formação do clima organizacional, sendo evidenciada fortemente por sua presença em diversos modelos de avaliação de clima (LITWIN; STRINGER, 1968; LUZ, 2012; MÓL, 2010, entre outros).

Diretamente relacionada ao sistema de recompensas, a remuneração está entre os aspectos que podem levar ao desligamento do trabalhador se ele perceber que há um desequilíbrio acentuado entre o esforço empreendido para a realização das tarefas e o 
reconhecimento na forma de salários e benefícios obtidos. Longo (2007) destaca que os trabalhadores, ao compararem os salários e benefícios recebidos, tanto inteiramente na organização, quanto externamente no mercado, avaliam a remuneração sob duas perspectivas de equidade: a interna, que se relaciona à estrutura remuneratória da organização e envolve, essencialmente, a evolução salarial ao longo da carreira, e a equidade externa, que se fundamenta na remuneração oferecida pelos concorrentes e outras organizações que atuam no mercado.

Tabela 5 Fator Remuneraçã

\begin{tabular}{lccc}
\hline Variáveis & Carga & $\mathrm{h}^{2}$ \\
\hline $\begin{array}{l}\text { A remuneração que recebo é compatível com outros profissionais que executam } \\
\text { tarefas semelhantes em organizações privadas. }\end{array}$ & 0,872 & 0,807 \\
$\begin{array}{l}\text { A remuneração que recebo é compatível com outros profissionais que executam } \\
\text { tarefas semelhantes em outros órgãos do poder federal. }\end{array}$ & 0,841 & 0,790 \\
Sinto-me satisfeito com a remuneração que recebo. & 0,594 & 0,635 \\
\hline
\end{tabular}

Fonte: Pesquisa de campo.

\subsection{REGRESSÃO LINEAR MÚLTIPLA}

A investigação da relação entre os fatores e a avaliação geral do clima organizacional foi feita com regressão linear múltipla (RLM), pelo método Backward, tomando os valores dos escores fatoriais como variáveis independentes (VI) e a variável "No geral, estou satisfeito com o clima organizacional no meu local de trabalho" como variável dependente (VD). A Tabela 5 mostra que a média da variável dependente foi $3,70( \pm 1,21)$, pouco acima da mediana da escala $(3,00)$, o que sugere uma avaliação levemente satisfatória do clima organizacional.

A estimação do modelo mostrou alto poder explicativo, com 70,81\% (R-quadrado ajustado) da variância da satisfação geral com o clima organizacional sendo explicada pelos regressores. Esse resultado é muito satisfatório para pesquisas sociais e indica que os fatores identificados exercem forte influência no clima organizacional. Os pressupostos da regressão linear múltipla (RLM) foram observados e atendidos, uma vez que o Teste F (significativo a $1 \%$ ) revelou que pelo menos uma das variáveis independentes exercia influência na variável dependente. Os resíduos mostraram distribuição normal e independente e se observou que, como esperado a priori, havia ausência de multicolinearidade, pois os escores fatoriais obtidos pela rotação Varimax são naturalmente ortogonais. Esse aspecto foi confirmado pela 


\section{OS FATORES QUE INFLUENCIAM NO CLIMA ORGANIZACIONAL EM INSTITUIÇÕES FEDERAIS DE ENSINO SUPERIOR: UMA INVESTIGAÇÃO BELÉM DO PARÁ, BRASIL DOI: http://dx.doi.org/10.5007/1983-4535.2019v12n1p25}

Estatística VIF, que obteve valor unitário para todas as variáveis independentes. Finalizando a investigação da violação das hipóteses da regressão, o teste de White resultou na ausência de heterocedasticidade, possibilitando avaliar o modelo como adequado para a interpretação do clima organizacional.

Tabela 6 Regressão linear múltipla

\begin{tabular}{lclccc}
\hline \multicolumn{7}{l}{ VD: Avaliação Geral do Clima Organizacional } \\
\hline Variáveis & Coeficiente & Erro Padrão & Razão-t & p-valor & Sig \\
\hline Constante & 3,69915 & 0,0428916 & 86,2443 & $<0,0001$ & $* * *$ \\
F1- Chefia & 0,36511 & 0,0429827 & 8,4945 & $<0,0001$ & $* * *$ \\
F2- Imagem organizacional & 0,66541 & 0,0429827 & 15,4810 & $<0,0001$ & $* * *$ \\
F3- Treinamento & 0,53365 & 0,0429827 & 12,4155 & $<0,0001$ & $* * *$ \\
F4- Remuneração & 0,44741 & 0,0429827 & 10,4091 & $<0,0001$ & $* * *$ \\
\hline Média var. dependente & 3,699153 & D.P. var. dependente & 1,219766 \\
Soma resíduos quadrados & 100,2923 & E.P. da regressão & 0,658913 \\
R-quadrado & 0,713155 & R-quadrado ajustado & 0,708188 \\
F (4, 231) & 143,5785 & P-valor (F) & $1,90 \mathrm{e}-61$ \\
Log da verossimilhança & $-233,8918$ & Critério de Akaike & 477,7836 \\
Critério de Schwarz & 495,1028 & Critério Hannan-Quinn & 484,7651 \\
\hline Teste da normalidade dos resíduos & Teste de White para a heteroscedasticidade \\
Hipótese nula: o erro tem distribuição normal & Hipótese nula: sem heteroscedasticidade \\
Estatística de teste: Qui-quadrado (2) =2,37497 & Estatística de teste: LM = 15,0407 \\
P-valor = 0,304987 & P-valor = P (Qui-quadrado (14) > 15,0407) $=0,375375$ \\
\hline
\end{tabular}

Nota: *** Significativo a $1 \%$.

Fonte: Pesquisa de campo

Os coeficientes com sinais positivos e significativos a $1 \%$ revelam que o modelo é coerente e possibilita observar que as melhorias na atuação das chefias, os investimentos na imagem organizacional e nos treinamentos dos servidores, além de melhores e mais modernas formas de remuneração, contribuem para um ambiente de trabalho mais saudável e produtivo, influenciando na formação de um clima organizacional favorável. Arabaci (2010), ao discorrer sobre o clima organizacional em instituições de ensino, destaca que existem relações muito próximas do clima com diversos aspectos do cotidiano dessas organizações. Contudo o autor se refere, em especial, a aspectos como confiança, senso de justiça e compromisso da organização. Notoriamente, ao longo do tempo, a educação assumiu destaque entre as diversas atividades humanas, tanto pelo caráter formador dos estudantes, quanto pela sua participação na criação de riqueza e desenvolvimento das nações.

Nesse contexto, organizações comprometidas com comportamentos socialmente aceitos como corretos alcançam maior reconhecimento e conseguem promover melhorias no ambiente de trabalho. Griffity (2006) reforça ao afirmar que os trabalhadores com percepção 
mais positiva do clima organizacional mostram também maior realização profissional e que ambientes ordenados e disciplinados, com relações pessoais agradáveis e equilibradas, contribuem para melhores níveis de desempenho dos estudantes.

O mesmo autor complementa ao afirmar que a percepção dos trabalhadores em relação ao seu local de trabalho desperta o interesse da psicologia social, aplicada há décadas, sendo esse interesse derivado, além de aspectos lógicos dessa ciência, da especial relação do ambiente com a produtividade, com a satisfação com o trabalho, com a qualidade dos serviços, com o absenteísmo e, inclusive, com o volume de negócios obtidos, materializados no desempenho pessoal e organizacional (STRINGER, 2002).

\section{CONSIDERAÇÕES FINAIS}

A pesquisa teve por objetivo analisar os aspectos que influenciam na formação do clima organizacional em instituições federais de ensino. Com esse propósito, a investigação foi conduzida em duas instituições da cidade de Belém do Pará. Os resultados revelaram uma estrutura multifatorial, formada por quatro fatores com forte influência no clima organizacional, uma vez que, juntos, eles foram capazes de explicar a maior parte da variância dos dados $(65,25 \%)$.

O primeiro fator foi relacionado com a atuação das chefias. Presentes em diversos modelos de avaliação de clima organizacional, esses profissionais são considerados um dos principais agentes do clima organizacional. O segundo fator foi a imagem organizacional, apesar de ser um elemento de destaque para qualquer organização moderna, em instituições de ensino, essa preocupação assume relevância ainda maior, especialmente pelo fato de a educação ter notório papel social. O terceiro fator foi o treinamento, entendido como uma forma de alcançar níveis mais elevados na carreira e no desempenho no trabalho. Esse fator revelou outro aspecto que merece a atenção dos gestores, uma vez que a carreira pública ainda reúne grande número de tarefas rotineiras e burocráticas, que, ao serem associadas à falta de objetivos claros para muitos cargos públicos, contribuem negativamente para o clima organizacional. Nesse aspecto, o treinamento é uma forma de promover novos aprendizados e mobilizar os servidores em atividades conjuntas. O quarto fator foi a remuneração, cujos resultados evidenciaram a necessidade de a administração pública promover uma estrutura remuneratória compatível com as atividades desenvolvidas e com o mercado de trabalho. 
Os resultados da regressão linear múltipla, verificadas as hipóteses, validaram o modelo e reforçaram o destaque para a imagem organizacional, que foi o fator que exerceu maior influência no clima organizacional; na sequência, em ordem decrescente, posicionaramse o treinamento, a remuneração e chefia. A adequação do modelo validou os fatores e indicou que eles podem ser utilizados como orientação de estratégias de gestão de pessoas nas instituições pesquisadas. Outras pesquisas podem ser feitas partindo dos achados desse estudo para aprofundar essas conclusões, especialmente investigando amostras probabilísticas.

\section{REFERÊNCIAS}

ARABACI, I. B. Academic and administration personnel's perceptions of organizational climate: sample of educational faculty of Firat University. Procedia. Social and Behavioral Sciences, v. 2, n.2, p. 4445-4450, 2010. Acesso em: 07 jun. 2017.

BERGUE, S.T. Modelos de gestão em organizações públicas. Caxias do Sul: Educs, 2011.

BOOG, G. G.; BOOG, M. Discursos e práticas de gestão de pessoas e equipes. Rio de Janeiro: Elsevier, 2012.

BRASIL, Decreto $n^{\circ} 5707$ de 23 de fevereiro de 2006. Disponível em: http://www.planalto.gov.br/ccivil_03/_ato2004-2006/2005/lei/111091.htm. Acesso em: 5 jun. 2017.

CONTRERAS, F. et al. Estilos de liderazgo, clima organizacional y riesgos psicosociales en entidades del sector salud. Un estudio comparativo. Acta Colombiana de Psicologia, v. 12, n.2, p. 13-26, jul./dez. 2009.

COSTA, F. J. Mensuração e desenvolvimento de escalas. Rio de Janeiro: Ciência Moderna, 2011.

COSTA, G. P. Heranças patrimonialistas, (Dis)funções burocráticas, práticas gerenciais e os novos arranjos do Estado em rede: entendendo a configuração atual da administração pública brasileira. Rio de Janeiro: FGV; EBAPE, 2012.

CUNHA, J. V. A.; COELHO, A. C. Regressão linear múltipla. In: CORRAR, L. J.; PAULO, E.; DIAS FILHO, J. M. Análise multivariada. São Paulo: Atlas, 2009.

DILLON, W. R.; GOLDSTEIN, M. Multivariate analysis: methods and applications. New York, John Wiley \& Sons, 1984.

DUTRA, J. S. Gestão de pessoas articulada por meio de competências. In: TEIXEIRA, H; J.; BASSOTTI, M.; SANTOS, T.S. Contribuições para a gestão de pessoas na administração pública. São Paulo: FIA/USP, 2013. 
FÁVERO, L. P. et al. Análise de dados: modelagem multivariada para tomada de decisões. São Paulo: Campus, 2009.

FOREHAND, G.A; GILMER, B. H. Environmental variation in studies of organizational behavior, Psychological Bulletin, v. 62, n. 6, p. 361-382, 1964.

GEMELLI, I. M. P.; FILIPPIM, E. S. Gestão de pessoas na administração pública: o desafio dos municípios. RACE, Unoesc, v. 9, n. 1-2, p. 153-180, jan./dez. 2010.

GHANBARI, S.; ESKANDARI, A. Organizational climate, job motivation and organizational citizenship behavior. International Journal os Management Perspective, v.1, n. 3, p. 1-14. jul./set, 2009.

GONÇALVES, C.A.M. Cultura e clima organizacional: contributos da motivação e das competências de gestão de líderes. Mangualde: Pedagogo, 2012.

GRIFFITH, J. A compositional analysis of the organizational climate-performance relation: public schools as organizations. Journal of Applied Social Psychology, v.35, n.8, p. 18401880, agu. 2006.

HAIR Junior, J. F. et al. Análise multivariada de dados. Porto Alegre: Bookman, 2009.

HOLLOWAY, J. B. Leadership Behavior and organizational climate: na empirical study in a non-profit organizational. Energing Leandership Journeys, v.5, n. 1, p. 9 -35. 2012.

HONG, L.C.; KAUR, S. A relationship between organizational climate, employee personality and intention to leave. International Review of Business Research Papers, v. 4, n. 3, p. 110, jun. 2008.

KJELDSEN, A.M.; HANSEN, J.R. Sector differences in the public service motivation- job satisfaction relationship: exploring the role organizational characteristics. Review of Public Personnel Administration, Online First, p. 1-25, fev. 2016.

KLEIN, F.A.; MASCATRNHAS, A.O. Motivação, satisfação profissional e evasão no serviço público: o caso da carreira de especialista em políticas públicas e gestão governamental. Revista de Administração Pública, v. 50, n, 1, p. 17-39, jan. / fev. 2016.

KOENE, B. A, S.; VOGELAAR, L.W.; SOETERS, J. Leadership effects on organizational climate and financial performance: local leadership effect in chain organizations. The Leadership Quarterly, v. 13, n. 3, p. 193-215, jun. 2002.

KUBO, E. K. M. et al. Frankenstein e o clima organizacional: estudo bibliográfico sobre um construto indefinido. Revista Internacional de Investigación em Ciencias Sociales, v. 11, n. 1, p. 35-54, jan./jul., 2015.

LITWIN, G. H; STRINGER, R. A. Motivation and organizacional climate. Cambridge: Havard University Press, 1968. 
LONGO, F. Mérito e flexibilidade: gestão das pessoas no setor público. São Paulo: Fundap, 2007.

LÜCK, H. Gestão da cultura e do clima organizacional da escola. Petrópolis: Vozes, 2011.

LUZ, R.S. Gestão do clima organizacional. Rio de Janeiro: Qualitymark, 2012.

MARCONI, M. A.; LAKATOS, E. Técnicas de pesquisa. São Paulo: Atlas, 2008.

MARTINS, G. A.; THEÓPHILO, C.R. Metodologia na investigação científica para ciências sociais aplicadas. São Paulo: Atlas, 2016.

MARTINS, M. C. F. Clima organizacional. In: SIQUEIRA, M. M. M. Medidas do comportamento organizacional: ferramentas de diagnóstico e de gestão. Porto Alegre:

Artmed, 2008.

MATIAS, A. C. M. Clima organizacional e satisfação laboral: um estudo sobre os núcleos hospitalares de epidemiologia de Natal/RN. Natal, 2010.

MATIAS-PEREIRA, J. Manual de gestão pública contemporânea. São Paulo: Atlas, 2012.

McCLELLAND, D. C. The achieving society. Princeton, NJ, Van Nostrand, 1961.

MINGOTI, S. A. Análise de dados através de métodos de estatística multivariada: uma abordagem aplicada. Belo Horizonte: Editora UFMG, 2007.

MELLO; M. L. B. C; AMÂNCIO FILHO, A. A gestão de recursos humanos em uma instituição pública brasileira de ciência e tecnologia em saúde: o caso Fiocruz. Revista de Administração Pública, v.44, n.3, p. 613-636, mai./jun. 2010.

MÓL, A. L. R. et al. Clima organizacional na administração pública. Rio de Janeiro: FGV, 2010.

MOMENI, N. The relation between managers' emotional intelligence and the organizational climate they create. Public Personnel Management, v. 38, n. 2, p. 35-88, jun. 2009.

MOTA, E. B.; SILVA, E. R. F.; PORTO, S. Nova administração pública: gestão municipal e tendências contemporâneas. Brasília, DF: Confederação Nacional dos Municípios, v.6, 2008 .

NOORDIN, F. et al. Organizational climate: a case of academics and administrative staff. International Journal of Science Commerce and Humanities, v.1, n.8, p. 43-51, dec. 2013.

OLIVEIRA, A. M. A influência do clima organizacional na motivação dos servidores da Fundação Alfredo da Matta. Rio de Janeiro, 2008. Disponível em:

$<\underline{\text { http://bibliotecadigital.fgv.br/dspace/handle/10438/3468>. Acesso em: } 25 \text { abr. } 2017 .}$ 
PELZ D.; ANDREWS, F. Scientists in organizations: productive climates for research and development. New York, Wiley, 1966.

PUROHIT, B.; WADHWA, A, Organizational climate from view point of motivation in district hospital, India. Health, v. 4, n. 7, p. 400-406, jul. 2012.

RUEDA, F. J. M.; SANTOS, A. A, A.; LIMA, R.C. Relação entre satisfação no trabalho e clima organizacional: um estudo com trabalhadores. Boletim de Psicologia, v. LXII, n. 137, p. 129-140, dez. 2012

SAMPIERI, R. H.; COLLADO, C. F.; LUCIO, P. B. Metodologia de pesquisa. São Paulo: McGraw-Hill, 2013.

SANTOS, N. M. B. F. Clima organizacional: pesquisa e diagnóstico. Lorena: Stiliano, 1999.

SBRAGIA, R. Um estudo empírico sobre clima organizacional em instituições de pesquisa.

Rev. Adm., São Paulo, v. 18, n. 2, abr./jun. p.7-17, 1983.

SILVA, F.M.; MELLO, S.P.T. Implantação da gestão por competências: práticas e resistências no setor público. Revista Eletrônica de Administração e Turismo, v.2. n.1, jan./jun. 2013..

SILVESTRE, H. C. Gestão pública: modelos de prestação no serviço público. Lisboa: Escolar, 2010.

STRINGER, R. A. Leadership and organizational climate: the cloud chamber effect. New Jersey: Prentice Hall, Upper saddler, 2002.

TEIXEIRA, H. J.; SALOMÃO, S.M. Visão sistêmica e gestão de pessoas. In: TEIXEIRA, H; J.; BASSOTTI, M.; SANTOS, T.S. Contribuições para a gestão de pessoas na administração pública. São Paulo: FIA/USP, 2013. 